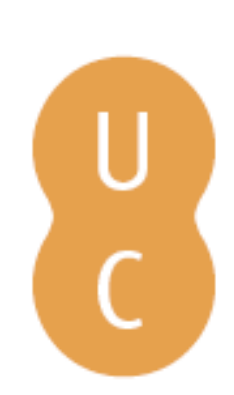

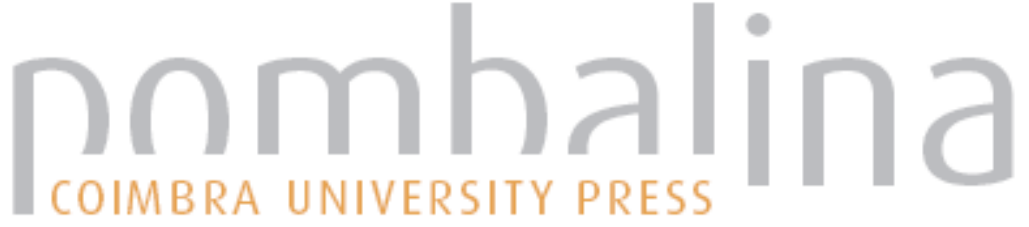

\section{Um olhar sobre o poder imperial em Suetónio}

Autor(es): $\quad$ Brandão, José Luís Lopes

Publicado por: Imprensa da Universidade de Coimbra

URL

persistente: URI:http://hdl.handle.net/10316.2/45226

DOI: $\quad$ DOI:https://doi.org/10.14195/978-989-26-1626-1_17

Accessed : $\quad$ 26-Apr-2023 04:17:55

A navegação consulta e descarregamento dos títulos inseridos nas Bibliotecas Digitais UC Digitalis, UC Pombalina e UC Impactum, pressupõem a aceitação plena e sem reservas dos Termos e Condições de Uso destas Bibliotecas Digitais, disponíveis em https://digitalis.uc.pt/pt-pt/termos.

Conforme exposto nos referidos Termos e Condições de Uso, o descarregamento de títulos de acesso restrito requer uma licença válida de autorização devendo o utilizador aceder ao(s) documento(s) a partir de um endereço de IP da instituição detentora da supramencionada licença.

Ao utilizador é apenas permitido o descarregamento para uso pessoal, pelo que o emprego do(s) título(s) descarregado(s) para outro fim, designadamente comercial, carece de autorização do respetivo autor ou editor da obra.

Na medida em que todas as obras da UC Digitalis se encontram protegidas pelo Código do Direito de Autor e Direitos Conexos e demais legislação aplicável, toda a cópia, parcial ou total, deste documento, nos casos em que é legalmente admitida, deverá conter ou fazer-se acompanhar por este aviso.

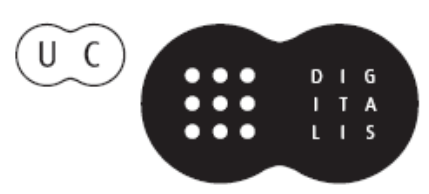




\section{Arqueologias de Império}

\section{Delfim Leão, José Augusto Ramos, Nuno Simões Rodrigues (coords.)}

IMPRENSA DA UNIVERSIDADE DE COIMBRA 


\title{
UM OLHAR SOBRE O PODER IMPERIAL EM SUETÓNIO ${ }^{1}$ (A look over imperial power in Suetonius)
}

\author{
José Luís Lopes BRANDÃo \\ Universidade de Coimbra, Centro de Estudos Clássicos e Humanísticos \\ (iosephus@fl.uc.pt; ORCID: 0000-0002-3383-2474)
}

\begin{abstract}
Resumo - Ao escrever as Vidas dos Césares Suetónio torna patente a sua interpretação sobre o poder imperial e a forma como este deve ser exercido. Trata-se verdadeiramente de um novo e melhor Estado, fundado por Augusto, mas que assenta numa sucessão mal definida e imprevisível, na qual o destino desempenha o seu papel. Mas tal poder, sendo ilimitado e potencialmente incontrolável, está dependente do carácter de quem o possui, que pode oscilar entre um comportamento tirânico e individualista e uma atitude paternal e, por consequência, universalista, que abarca todas as áreas de intervenção governativa, todas as ordens, e todos os povos.
\end{abstract}

Palavras-CHaVe: biografia; Suetónio; poder; imperadores; Império Romano.

Aвstract - In writing the Lives of the Caesars Suetonius makes clear his interpretation on imperial power and the way in which it must be exercised. For him, the empire founded by Augustus is truly a new and better state, but based on an ill-defined and unpredictable succession, in which fate plays its part. Such power, being unlimited and potentially uncontrollable, is dependent on the character of the possessor, which can range from a tyrannical and individualistic behaviour to a paternal and therefore universalist attitude, encompassing all areas of government intervention, all Orders, and all people.

KEYwORDs: biography; Suetonius; power; emperors; Roman Empire.

Suetónio não questiona o poder imperial: trata-se de uma realidade incontestável e para ele desejável. No entanto, tal poder concretiza-se em imperadores vivos e está dependente deles, com as suas virtudes e vícios. A opção pela biografia, para transmitir a história política, equivale precisamente a reconhecer definitivamente que a política da Roma imperial já não era determinada pelo ciclo anual da eleição dos magistrados, mas pelo ciclo de vida de cada príncipe. A oposição tradicional da historiografia entre a virtude do passado e a decadência do presente ${ }^{2}$ é substituída pelo confronto entre bons e maus imperadores, ou entre o que cada qual tem em si de positivo e de negativo ${ }^{3}$.

\footnotetext{
${ }^{1}$ Trabalho desenvolvido no âmbito do projeto UID/ELT/00196/2013, financiado pela FCT - Fundação para a Ciência e a Tecnologia.

${ }^{2}$ Veja-se Giua 1990, 538. Muito do material aqui usado é reformulado a partir de Brandão $2009 \mathrm{~b}$.

${ }^{3}$ Consequentemente, ações que para o historiador antigo informam a trama narrativa, aparecem dispersas por rubricas de virtudes e vícios. Veja-se Wallace Hadrill 1984, 143.
} 


\title{
1. UMA NOVA ORDEM (STATUS).
}

Para Suetónio o poder imperial corresponde a um novo regime político, explicitamente distinto da República, mas que se começa a desenhar com Júlio César, e por isso inicia com ele o conjunto das Vidas. Os primeiros capítulos perdidos da Vida do ditador talvez nos esclarecessem sobre o plano do biógrafo, tal como Tácito, no início dos Annales (1), nos explica a razão porque começa pelos últimos momentos da vida de Augusto. Ao começar a redação das Vidas por Júlio César, e não por Augusto ${ }^{4}$, Suetónio coloca a tónica na natureza monárquica da transformação, que trata, assim, desde o início ${ }^{5}$. O biógrafo sublinha a continuidade nos objetivos, apesar da distinção nos meios para os concretizar.

Embora o próprio Augusto afirme nas Res Gestae (34) que transferiu a res publica do seu poder para o arbitrium do senado e do povo romano, Suetónio, realista, diz que o imperador pensou restabelecer a República, mas que ponderados os perigos a que ele e o Estado ficariam expostos, optou por mantê-lo em seu poder. E, de seguida, o biógrafo transmite a palavra a Augusto, através de um édito, onde este se apresenta como o autor de uma nova ordem ${ }^{6}$ :

\begin{abstract}
«Assim me seja permitido consolidar o Estado são e salvo nos seus fundamentos e daí recolher o fruto que almejo, de ser proclamado autor do melhor regime e de levar comigo, ao morrer, a esperança de que permanecerão no seu lugar os alicerces do estado que eu tiver lançado.' Ele mesmo se encarregou a si próprio do voto, esforçando-se de todos os modos para que ninguém ficasse insatisfeito com o novo regime».
\end{abstract}

Assim introduz Suetónio nas Vidas dos Césares a ideia do principado - um nouus status. Neste contexto não emprega o termo princeps, oriundo da tradição republicana ${ }^{7}$. Para caracterizar a preeminência de Augusto, usa o termo auctor, de modo a salientar que se trata de uma ordem nova, baseada na auctoritas, neste caso congruente com o que Augusto afirma no referido passo das Res Gestae, de que está acima de todos em autoridade e não em poder. Suetónio também

${ }^{4}$ Plutarco escreveu Vidas de oito imperadores, de Augusto a Vitélio, de que só restam as de Galba e Otão. Tácito começa pela ascensão de Tibério, porque acha que, para o governo de Augusto, existiam já autores com engenho (Ann. 1.1).

${ }^{5}$ Suetónio ao começar por César, vem consagrar um cânone de imperadores estabelecido na época de Trajano Cf. Tac. Ann 13.3; Plin. Ep. 5.3.5; App. Praef. 6. Veja-se La Penna 1987, 294.

${ }^{6}$ Aug. 28.2: 'Ita mihi saluam ac sospitem rem p. sistere in sua sede liceat atque eius rei fructum percipere, quem peto, ut optimi status auctor dicar et moriens ut feram mecum spem, mansura in uestigio suo fundamenta rei p. quae iecero.' Fecitque ipse se compotem uoti nisus omni modo, ne quem noui status paeniteret.

${ }^{7}$ E em Cal. 22.1, Suetónio fala de uma species principatus, demonstrando ter consciência de que o nome de princeps, e, por consequência, principatus, é uma forma hábil de iludir os legalistas. Se bem que neste passo também parece ser uma forma de caracterizar negativamente a fase considerada mais positiva do principado de Calígula. Veja-se Gascou 1984, 783-85. 
não expõe a habilidade política do fundador do principado, mas a qualidade dos efeitos do seu projeto. O intento, depois abandonado, de restaurar a República inspira a Suetónio um comentário que, embora se mostre ambíguo, parece sugerir aprovação: «é duvidoso se foi melhor o resultado ou a intenção ${ }^{8}$ », isto é, foi tão correta a atitude de ponderar como foi afortunado o facto de não levar avante o retorno ao Estado republicano9. Não sugere que a célebre sessão do senado de 27 a.C. fosse um golpe de teatro, mas que se tratou de uma escolha racional: o abandono ponderado de uma política conservadora em proveito de uma adequação realista aos tempos, de que resultou um optimus status. A expressão parece evocar Trajano, optimus princeps, sobretudo se nos lembrarmos que as Vidas dos Césares terminam com o elogio do beatior e laetior status, que viria depois de Domiciano graças às virtudes dos principes seguintes ${ }^{10}$.

\section{PODER APOIADO NUMA SUCESSÃo IMPREVISÍVEL}

Porque se trata de algo novo, os problemas da sucessão levantam-se de imediato com a morte de Augusto. A suspeita de hipocrisia domina a narrativa da aclamação de Tibério. Provavelmente a sua hesitação era sincera: a sucessão no principado era uma realidade sem precedentes. A situação do sucessor de Augusto era incómoda, pois tratava-se do herdeiro possível, como se torna claro pela transcrição de um excerto do testamento de Augusto ${ }^{11}$. Mas Suetónio interpreta a hesitação como uma farsa, se aceitarmos a lição impudentissimus mimus $^{12}$ («Ao principado, embora não hesitasse em ocupá-lo imediatamente e em exercêlo - tomou até para si uma guarnição de soldados, o que lhe conferia poder e uma forma de soberania - recusou-o longo tempo com uma farsa assaz descarada...»). Para o biógrafo, o uso de guarda-costas mostra que Tibério deseja o poder ${ }^{13}$, mas recusa-o hipocritamente ${ }^{14}$, para depois o aceitar, com

${ }^{8}$ Aug. 28.1: De reddenda re p. bis cogitauit: primum post oppressum statim Antonium, memor obiectum sibi ab eo saepius, quasi per ipsum staret ne redderetur; ac rursus taedio diuturnae ualitudinis, cum etiam magistratibus ac senatu domum accitis rationarium imperii tradidit. sed reputans et se priuatum non sine periculo fore et illam plurium arbitrio temere committi, in retinenda perseuerauit, dubium euentu meliore an uoluntate.

${ }^{9}$ Segundo a interpretação de Rolfe [1913-1914] 1979, 1:164, n.b (acolhida por Gascou 1984, 719), foram igualmente bons a intenção de Augusto de renunciar à República e os efeitos do novo regime.

${ }^{10}$ Dom. 23.2.

${ }^{11}$ Tib. 23.

${ }^{12}$ Tib. 24: Principatum, quamuis neque occupare confestim neque agere dubitasset, et statione militum, hoc est ui et specie dominationis assumpta, diu tamen recusauit impudentissimo mimo. Mimus é uma conjetura de Gronouius por comparação com Cal. 45.2; Otho 3.2; os manuscritos apresentam animo.

${ }^{13}$ A presença de guarda-costas era associada a tirania desde o tempo dos Pisístratos. Veja-se Lindsay 1995, 109. É seguida aqui uma tradição hostil a Tibério: veja-se Gascou 1984, 264-65.

${ }^{14}$ Tibério talvez estivesse a ser sincero: tinha já 54 anos e não podia ter pretensões de emular 
suspeita condescendência ${ }^{15}$ («Finalmente, como que forçado e queixando-se da infeliz e pesada servidão que lhe era imposta, aceitou o império, desde que não deixasse de poder acalentar a esperança de um dia o abandonar. São estas as palavras do próprio: 'até eu chegar à idade em que vos possa parecer justo dar algum repouso à minha velhice'») ${ }^{16}$.

Uma sucessão indefinida gera a tentação do crime, e a primeira vítima da luta pela sucessão imperial seria Agripa Póstumo, cujo assassinato terá precedido a divulgação da morte de Augusto ${ }^{17}$. Mas Suetónio, em alguns casos, descortina crime onde este não parece existir. Assim, diferentemente do relato da morte de Tibério na Vida do próprio ${ }^{18}$, a suposta responsabilidade de Calígula na supressão in extremis do antecessor aparece agravada na Vida do último ${ }^{19}$, de forma a transformar a sucessão numa espécie de usurpação criminosa. Da mesma forma, se, na Vida de Cláudio, a morte do imperador é atribuída à ação de Agripina ${ }^{20}$, na Vida de Nero, insinua-se a responsabilidade deste na morte do pai adotivo, para se concluir que, se não foi o auctor, pelo menos foi cúmplice (conscius) $)^{21}$. Também a ascensão de Domiciano ao governo do império é marcada pela hostilidade em relação a Tito. E, se, na Vida deste, a morte é apenas atribuída à doença, na Vida de Domiciano ${ }^{22}$, sugere-se que é apressada por ação (ou omissão) do sucessor, que abandona o irmão na agonia da doença ${ }^{23}$.

Suetónio não defende explicitamente a adoção enquanto escolha do melhor, como faz Tácito a propósito da escolha de Pisão por parte de Galba ${ }^{24}$, mas, entre

Augusto. Mas também era difícil contrariar a disposições testamentárias deste. Provavelmente Tibério precisava de tempo para definir o seu poder. Veja-se Seager 1972, 56-57; Syme 1974, 485-86; Levick 1999, 76.

${ }^{15}$ Tib. 24: Tandem quasi coactus et querens miseram et onerosam iniungi sibi seruitutem, recepit imperium; nec tam aliter, quam ut depositurum se quandoque spem faceret. Ipsius uerba sunt: 'dum ueniam ad id tempus, quo uobis aequum possit uideri dare uos aliquam senectuti meae requiem'.

${ }^{16}$ Para Timonen 1993, 133-48, Suetónio, em comparação com Tácito (Ann. 4.9.1), exagera a hesitação na mira de vituperar o principado de Tibério desde o início.

${ }^{17}$ Tib. 22.

${ }^{18}$ Tib. 73.2.

${ }^{19}$ Cal. 12.2. Cf. Tib. 73.2. O facto de autores como Fílon de Alexandria e Flávio Josefo não atribuírem a Calígula responsabilidade na morte de Tibério deve ser tomado a favor da inocência. Tácito (Ann. 6.50.4-5) atribui a Mácron a iniciativa de apressar a morte do velho imperador, e Díon Cássio (58.28.3) sustenta que a ordem partiu de Calígula, mas nenhum fala da participação directa no ato de sufocar o imperador.

${ }^{20} \mathrm{Cl} .44$.

${ }^{21}$ Nero 33.

${ }^{22}$ Dom. 2.3.

${ }^{23}$ Esta ideia é secundada por Díon Cássio (66.26.2), segundo o qual Domiciano, para apressar o fim, colocou Tito num cofre com gelo, sob o pretexto de que necessitava de refrigeração. Segundo Aurélio Victor (Caes. 10.5), Tito foi envenenado pelo irmão. Veja-se Martin 1991, 196; Gascou 1984, 385-86.

${ }^{24}$ Hist. 1.15-16. 
os sucessores de Augusto, todas as aclamações parecem ser problemáticas, à exceção de Tito, que mantém o poder que já partilhava com o pai. Porém, longe de contestar a aclamação, o biógrafo aceita os factos como são, porque determinados por forças transcendentes, o que nos remete para outro aspeto determinante do poder imperial.

\subsection{Poder dependente do fatum ou do acaso}

Tibério, que recorria aos conselhos do astrólogo Trasilo, estava convencido de que tudo era governado pelo destino ${ }^{25}$. $\mathrm{Na}$ verdade, o preâmbulo do referido testamento de Augusto vem revelar que foi a atrox fortuna que, ao arrebatar os filhos de Júlia, Gaio e Lúcio, provocou a escolha de Tibério como herdeiro. E a voz corrente, referida a seguir, de que a escolha se deve à necessitas, transforma o advento de Tibério num acontecimento fatídico, que o próprio Augusto não evitou (ou até acentuou) e que prenuncia males piores ${ }^{26}$. Tito advertirá uns conspiradores de que é ao fatum que cabe a tarefa de conceder o principado ${ }^{27}$. Com a construção da ponte de Barcas em Baias, Calígula, além de alardear o seu poder sobre os elementos e sobre os povos, parece querer simbolizar a sua vitória sobre o destino: uma das explicações para o evento foi o facto de o astrólogo Trasilo ter dito a Tibério que «Gaio seria tanto imperador como atravessaria o golfo de Baias a cavalo» ${ }^{28}$. Este fatalismo está também presente na generalização abusiva que encerra a Vida de Calígula: todos os Césares, cujo praenomen fosse Gaio, morreram assassinados ${ }^{29}$.

De facto, o religioso Suetónio, como o apresenta Plínio, parece sobrevalorizar esta conceção determinista da história e multiplica as referências a presságios ${ }^{30}$. A sucessão dos imperadores surge enquadrada por um plano transcendente: Augusto, Galba ou Vespasiano, segundo os presságios apresentados ${ }^{31}$, estão há muito tempo destinados ao governo do orbe. A hora do parto de Augusto, segundo um pitagórico especialista em astrologia, promete um dominus terrarum ${ }^{32}$. Eles próprios se apresentam como conscientes desta trama transcendente. Augusto e Tibério sabem que Galba será um sucessor ${ }^{33}$. Vespasiano prevê que são os filhos a suceder-lhe ${ }^{34}$ e que Domiciano deve temer o ferro ${ }^{35}$.

${ }^{25}$ Tib. 69.

${ }^{26}$ Contudo, Augusto só estava a justificar legalmente a adoção de Tibério: veja-se Wiedemann 1989, 19.

${ }^{27}$ Tit. 9.1.

${ }^{28}$ Veja-se Wardle 1994, 70.

${ }^{29}$ Cal. 60. Veja-se Wardle 1994, 372; Hurley 1993, 217.

${ }^{30}$ Sobre este assunto, veja-se Brandão 2013, 285-95.

${ }^{31}$ Aug. 93.1 ss; Gal. 9.2; Ves. 4.5. Veja-se Gascou 1984, 77585.

${ }^{32}$ Aug. 94.5 .

${ }^{33}$ Gal. 4.1.

${ }^{34}$ Ves. 25.

${ }^{35}$ Dom. 14.1 . 
Por outro lado, Suetónio constata que Cláudio alcança o poder por um acaso extraordinário (mirabilis casus) ${ }^{36}$. O biógrafo compraz-se a descrever amiúde situações que por pouco não alteraram o curso dos acontecimentos. Daí a importância atribuída à arte divinatória, manifesta na valorização de determinadas coincidências ${ }^{37}$.

\section{NÃO SE TRATA DE DOMINATIO OU REGNUM}

A propaganda destinada a afastar a ideia de que era um tirano está implícita na atuação de Augusto. Fora esse o principal erro de César, cuja ambição de reinar é continuamente sugerida ao longo da Vida. Logo no princípio, Suetónio transcreve um excerto do elogio fúnebre da tia de César onde o próprio exalta a origem real e divina da família ${ }^{38}$. É significativa da sua ambição a frase que César repete ao tomar conhecimento das resoluções tomadas no senado em seu desfavor ${ }^{39}$ : («mais dificilmente o expulsariam do primeiro para o segundo lugar entre os cidadãos do que do segundo para o último»).

O pretexto que leva à travessia do Rubicão é a violência do senado contra os tribunos da plebe, que, com o veto, intercediam por César, mas as verdadeiras causas seriam outras ${ }^{40}$ : o medo de, reduzido a cidadão privado, ser castigado por irregularidades cometidas no exercício do primeiro consulado ${ }^{41}$, e sobretudo a ambição da tirania (dominatio) ${ }^{42}$. Ele próprio citava amiúde um verso de Eurípides segundo a qual, a ambição reinar justifica a violação da justiça e do respeito pelos deuses ${ }^{43}$.

Mais à frente, são apresentados facta dictaque que fazem com que se considere que abusou da tirania (dominatio) e que, por conseguinte, a morte é justa ${ }^{44}$ :

${ }^{36}$ Cl. 10. Cf. D.C. 60.1.3-4, e I. AI 19.212-25. Veja-se Martin 1991, 229-30.

${ }^{37}$ Cl. 2.1; Nero 40.4; Nero 57.1; Gal. 6.1; Tit.1.

${ }^{38} \mathrm{Jul}$. 6.1: Est ergo in genere et sanctitas regum, qui plurimum inter homines pollent, et caerimonia deorum, quorum ipsi in potestate sunt reges. Veja-se Canfora 2000, 17-18.

${ }^{39} \mathrm{Jul}$. 29.1: difficilius se principem ciuitatis a primo ordine in secundum quam ex secundo in nouissimum detrudi. Plutarco (Caes. 11.3-4), coloca a frase noutro contexto (no caminho para a Hispânia enquanto propretor), mas o significado é semelhante. Veja-se Canfora 2000, 145-46.

${ }^{40} \mathrm{Jul}$. 30.2: Et praetextum quidem illi ciuilium armorum hoc fuit; causas autem alias fuisse opinantur.

${ }^{41}$ Jul. 30.3-4: Alii timuisse dicunt, ne eorum, quae primo consulatu aduersus auspicia legesque et intercessiones gessisset, rationem reddere cogeretur ... Quod probabilius facit Asinius Pollio, Pharsalica acie caesos profligatosque aduersarios prospicientem haec eum ad uerbum dixisse referens: 'hoc uoluerunt; tantis rebus gestis Gaius Caesar condemnatus essem, nisi ab exercitu auxilium petissem'.

${ }^{42} \mathrm{Jul}$. 30.5: Quidam putant captum imperii consuetudine pensitastisque suis et inimicorum uiribus usum occasione rapiendae dominationis quam aetate prima concupisset.

${ }^{43} \mathrm{Jul}$. 30.5. Trata-se de uma parte do discurso de Etéocles (E. Ph. 524), que Cícero traduz por Nam si uiolandum est ius, <regnandi> gratia / uiolandum est: aliis rebus pietatem colas. Veja-se Canfora 2000, 153; Romilly 1969, 183-84 e 186-87.

${ }^{44} \mathrm{Jul}$. 76.1: Praegrauant tamen cetera facta dictaque eius, ut et abusus dominatione et iure caesus existimetur. 
honras exageradas; privilégios que superam o humanum fastigium, e uma atuação política onde impera a arbitrariedade (licentia) e o desrespeito pelo patrius mos ${ }^{45}$. Tais honras são agravadas por uma série de ditos célebres (dicta) que manifestam excesso (inpotentia) contra a res publica, e arrogantia face aos presságios ${ }^{46}$. Além disso, César não se livra da infamia de que desejaria o título de rex, apesar de afirmar que «era César e não rei» e de, durante as Lupercais, afastar - gesto teatral suspeito - a coroa que António repetidamente lhe colocava sobre a cabeça e de a consagrar a Júpiter Óptimo Máximo ${ }^{47}$.

Torna-se pois claro que princeps ou imperator se distanciam dominus ou tyrannus ${ }^{48}$. Porém, a diferença entre princeps e dominus não é de carácter constitucional, mas sobretudo de natureza moral ${ }^{49}$. O êxito de Augusto fica a dever-se à demarcação em relação a César, manifesta em atitudes teatrais que o biógrafo não desmascara: a recusa de templos e estátuas de ouro, a rejeição aparatosa da ditadura, acompanhada de atitudes de súplica ${ }^{50}$, manifestação de horror ao apelido de dominus, ostensivamente conotado com «maldição e desonra» ${ }^{51}$, e o respeito pelo senado ${ }^{52}$ são apresentados como provas (documenta) da ciuilitas $^{53}$. Tal virtude traduz a consciência de cidadão, a rejeição da monarquia de tipo oriental e da tirania (dominatio), e defesa da libertas ${ }^{54}$, entendida, durante o principado, sobretudo como liberdade de expressão. Ao contrário de César, que pelo abusus dominatione e pela inpotentia mereceu a morte, Augusto é objecto da estima geral ${ }^{55}$, tornando-se, assim, um modelo para os sucessores.

Tibério, de formação republicana, revela ciuilitas, a princípio: ao recusar maximi honores que incluíam culto divino ${ }^{56}$, rejeita o praenomen de imperator, o

${ }^{45} \mathrm{Jul}$. 76.3: Eadem licentia spreto patrio more magistratus in pluris annos ordinauit... eoque arrogantiae progressus est (...)

${ }^{46} \mathrm{Jul}$. 77: Nec minoris inpotentiae uoces propalam edebat (...)

${ }^{47} \mathrm{Jul}$. 79.2: Neque ex eo infamiam affectati etiam regii nominis discutere ualuit, quamquam et plebei regem salutanti 'Caesarem se, non regem esse' responderit et Lupercalibus pro rostris a consule Antonio admotum saepius capiti suo diadema reppulerit atque in Capitolium Ioui Optimo Maximo miserit.

${ }^{48}$ Veja-se Bradley 1991, 3715-716. Nota Gascou 1984, 721-22, que, neste ponto, Suetónio está de acordo com Plínio (Pan. 45.3): Scis ut sunt diuersa natura dominatio et principatus, ita non aliis esse principem gratiorem quam qui maxime dominum grauentur. Cf. Cic. Rep. 1.50.

${ }^{49}$ Como sublinha Gascou 1984, 721-22.

${ }^{50}$ Aug. 52.

${ }^{51}$ Aug. 53.1: Domini appellationem ut maledictum et obprobrium semper exhorruit. Suetónio não denuncia a habilidosa simulação de horror.

${ }^{52}$ Aug. 53.3.

${ }^{53}$ Aug. 51.1: Clementiae ciuilitatisque eius multa et magna documenta sunt. A ciuilitas, a par da clementia, vem, em Suetónio, associada à moderatio, como demonstra Gascou 1984, 722-23.

${ }^{54}$ Cf. Aug. 54: Nec ideo libertas aut contumacia fraudi cuiquam fuit.

${ }^{55}$ Aug. 57.1: Pro quibus meritis quanto opere dilectus sit, facile est aestimare.

${ }^{56}$ Tib. 26.1: Verum liberatus metu ciuilem admodum inter initia ac paulo minus quam priuatum egit. Ex plurimis maximisque honoribus praeter paucos et modicos non recepit. Na Vida de Tibério não parece haver diferença, como mostra Gascou 1984, 723, entre ciuilitas e moderatio, 
cognomen de pater patriae, a coroa cívica; limita o uso do nome de Augusto, que herdou, às cartas dirigidas aos reis $^{57}$, e sobretudo recusa o apelido de dominus ${ }^{58}$ e defende repetidamente a liberdade de expressão e de pensamento ${ }^{59}$, chegando mesmo a restabelecer o que o biógrafo designa por uma species libertatis ${ }^{60}$. Também Cláudio revela ciuilitas ao recusar o praenomen de imperator e honras excessivas $^{61}$ e ao mostrar respeito pelo senado e magistrados ${ }^{62}$. Quanto a Vespasiano, mostra-se ciuilis et clemens do início ao fim do principado ${ }^{63}$. Tais diferenças são pois decorrentes do carácter individual e dificilmente podem ser prevenidas.

\section{Poder ilimitado e ético.}

Como não há formas constitucionais de controlar o poder do imperador, as restrições são apenas de ordem ética: dependem do carácter pessoal, objecto privilegiado de análise da biografia. Palavras atribuídas a Calígula e a Nero revelam o deslumbramento que pode causar este poder ilimitado. O primeiro, a uma repreensão da avó Antónia, responde ${ }^{64}$ : «Hás-de lembrar-te que tudo me é permitido contra todos!» Nero, como que fascinado com a impunidade com que comete parricidia et caedes ${ }^{65}$, «disse que nenhum dos príncipes fazia ideia do que lhe era permitido».

$\mathrm{O}$ autocontrolo e equilíbrio são difíceis de manter, quando se possui tal poder (in imperio), comenta o biógrafo ${ }^{66}$. Há o risco de enveredar pela inpotentia

visto que depois (Tib. 32.2) afirma: Parem moderationem minoribus quoque et personis et rebus exhibuit; e em outro passo, Tib. 57.1: (...) etiam inter initia cum adhuc fauorem hominum moderationis simulatione captaret.

${ }^{57}$ Tib. 26.2.

${ }^{58}$ Tib. 27.

${ }^{59}$ Tib. 28: Sed et aduersus conuicia malosque rumores et famosa de se ac suis carmina firmus ac patiens subinde iactabat 'in ciuitate libera linguam mentemque liberas esse debere'.

${ }^{60}$ Tib. 30: Quin etiam speciem libertatis quandam induxit conseruatis senatui ac magistratibus et maiestate pristina et potestate. Também Tácito (Ann. 1.77.3) fala de simulacra libertatis.

${ }^{61} \mathrm{Cl}$. 12.1: At in semet augendo parcus atque ciuilis praenomen Imperatoris abstinuit, nimios honores recusauit.

${ }^{62} \mathrm{Cl}$. 12.2. Atitudes que lhe valeram amor e fauor: $\mathrm{Cl}$. 12.3: Quare in breui spatio tantum amoris fauorisque collegit.

${ }^{63}$ De âmbito semântico próximo é a comitas, a afabilidade ilustrada através do sentido de humor de Vespasiano; Ves. 22: Et super cenam autem et semper alias comissimus multa ioco transigebat...

${ }^{64}$ Cal. 29.1: 'memento', ait, 'omnia mihi et <in> omnis licere'. E ao primo Gemelo, suspeitando de que ele tomava um contraveneno: 'Antidotum', inquit, 'aduersus Caesarem?' Ameaça as irmãs relegadas de que não dispunha só de ilhas, mas também de espadas; repete um verso trágico típico de um carácter tirânico (Cal. 30.1): 'oderint, dum metuant', expressão retirada do Atreu de Ácio. Cf. Tib 59.2: oderint, dum probent.

${ }^{65}$ Ves. 12; Nero 33 ss; Nero 37.3: Elatus inflatusque tantis uelut successibus negauit 'quemquam principum scisse quid sibi liceret'.

${ }^{66}$ Esta constatação encarece o carácter de Tito - Tit. 1: (...) tantum illi ad promerendam omnium uoluntatem uel ingenii uel artis uel fortunae superfuit, et quod difficillimum est, in imperio... 
ou arrogantia ou superbia ${ }^{67}$. A intenção de substituir a species principatus pelo regnum $^{68}$ e o desejo de autodivinização ${ }^{69}$ iniciam a narrativa da parte que diz respeito à descrição de Calígula enquanto monstrum. Quanto a Domiciano, a propensão para a dominatio manifesta-se desde a juventude ${ }^{70}$; e, quando imperador, aceita com agrado que o apelidem de dominus ${ }^{71}$, e com a mesma arrogantia autoproclama-se dominus et deus ${ }^{72}$, recebe honras, que, como César e Calígula, ultrapassam os limites humanos ${ }^{73}$, ao ponto de, como eles, se tornar odiado e ser castigado com a morte violenta que impende sobre os tiranos ${ }^{74}$. Sintomática é, por isso, a relação dos imperadores com o senado, que de algum modo é símbolo do regime republicano. Nero chega a pensar em eliminar este órgão ${ }^{75}$, e Calígula não mostra para com ele reuerentia ou lenitas ${ }^{76}$.

Por outro lado, o bom princeps sabe moderar a sua cólera contra os inimigos e respeita a propriedade. No exercício do poder, a moderatio opõe-se à arrogância da atuação tirânica e à crueldade ${ }^{77}$. Implica a prática da clementia, cujo vício oposto é a saeuitia ou crudelitas. Esta é uma virtude que César evidencia, o que o afasta da imagem de um tirano completo. A par da moderatio, Suetónio, no final da Vida de Domiciano ${ }^{78}$, coloca a abstinentia como virtude fundamental para o desempenho do bom príncipe. Esta virtude implica o respeito pela propriedade alheia; impede que o imperador use o seu poder para conseguir lucros indevidos. A ausência desta virtude é notada no exercício do imperium e das magistraturas de César ${ }^{79}$. A abstinentia opõe-se à auaritia, à cupiditas, à rapacitas, que definem a atuação dos maus imperadores no que diz respeito aos bens dos cidadãos, mortos ou vivos, das cidades, das províncias, dos templos. Como auaritia designa

${ }^{67} \mathrm{O}$ traço típico do comportamento tirânico. Veja-se, a propósito de Plínio-o-Velho, Oliveira 1992, 26-27.

${ }^{68} \mathrm{Cal}$. 22.1: Nec multum afuit quin statim diadema sumeret speciemque principatus in regni formam conuerteret.

${ }^{69}$ Cal. 22.2: Verum admonitus et principum et regum se excessisse fastigium, diuinam ex eo maiestatem asserere sibi coepit.

${ }^{70}$ Dom. 1.3: ceterum omnem uim dominationis tam licenter exercuit, ut iam tum qualis futurus esset ostenderet. Dom. 12.3: Ab iuuenta minime ciuilis animi, confidens etiam et cum uerbis tum rebus immodicus.

${ }^{71}$ Dom. 13.1.

${ }^{72}$ Dom. 13.2.

${ }^{73}$ Dom. 13.2-3.

${ }^{74}$ Dom. 14.1: Per haec terribilis cunctis et inuisus, tandem oppressus est.

${ }^{75}$ Nero 37.3.

${ }^{76}$ Cal. 26.2: Nihilo reuerentior leniorue erga senatum (...) Cal. 49.1: Edixit et 'reuerti se, sed iis qui optarent, equestri ordini et populo; nam se neque ciuem neque principem senatui amplius fore'. Cf. Cal. 26.2. A superbia e a uiolentia qualificam, em geral, a sua relação com as diferentes classes (Cal. 26.4; 30.2). Na altura da morte, projetava facinora maiora, como a eliminação dos membros mais eminentes das classes senatorial e equestre (Cal. 8).

${ }_{77}$ Veja-se Gascou 1984, 724-25.

${ }^{78}$ Dom. 23.2.

${ }^{79} \mathrm{Jul}$. 54.1: Abstinentiam neque in imperiis neque in magistratibus praestitit. 
Suetónio a avidez de riquezas de $\mathrm{Nero}^{80}$, mas também a mesquinhez de Galba ${ }^{81}$, vício que inclusivamente contribuirá para a sua queda. A cupiditas pecuniae é apresentada como o único vício de Vespasiano ${ }^{82}$, de cuja fama se não consegue livrar ${ }^{83}$, e como segundo vício de Domiciano, suplantado apenas pela crueldade $(\text { saeuitia })^{84}$.

A divisão operada na biografia de Calígula entre atos do princeps e atos do monstrum, ou na de Nero entre factos louváveis e neutros por um lado e probra ac scelera por outro demonstram que Suetónio opera uma consideração moral de toda a atuação destes príncipes. O mesmo se depreende do facto de a morte dos maus imperadores tender a ser apresentada como um castigo da tirania ${ }^{85}$.

\section{Poder paternalista.}

Na sociedade romana imperial, que apresenta uma pirâmide de laços de clientela, o princeps não deve ser um dominus, mas um patronus para os cidadãos, para as cidades de Itália, para as províncias, para os reis aliados ${ }^{86}$. Além da abstinentia, exige-se de um príncipe a liberalitas do primeiro dos patroni. Uma conceção "paternalista» do imperador está explícita, em particular, na forma como Tito acode às vítimas das calamidades, «não apenas com o zelo de um príncipe, mas também com amor ímpar de um pai ${ }^{87}$. Augusto exibe a liberalitas com todas as orden $s^{88}$. Vespasiano, depois de minimizada a má fama da cupiditas pecuniae, é definido como assaz generoso para com todos (in omne hominum genus liberalissimus $)^{89}$. A liberalitas figura explicitamente entre as virtudes ostentadas por Nero e Domiciano nos inícios destes principados ${ }^{90}$, quando pareciam prometedores.

Os príncipes manifestam, em geral, consciência da importância do evergetismo como sustentáculo do poder imperial. As enumerações apresentadas por Suetónio sugerem a importância social e política que o biógrafo atribui a estes

${ }^{80}$ Nero 26.1.

${ }^{81}$ Gal. 12.1 .

${ }^{82}$ Ves. 16.1: Sola est in qua merito culpetur, pecuniae cupiditas; Ves. 16.3: Quidam natura cupidissimum tradunt.

${ }^{83}$ Ves. 19.1: Et tamen ne sic quidem pristina cupiditatis infamia caruit.

${ }^{84}$ Ves. 1.1: (...) constet licet Domitianum cupiditatis ac saeuitiae merito poenas luisse; Dom 10.1: (...) et tamen aliquanto celerius ad saeuitiam desciuit quam ad cupiditatem (desenvolvimento em Dom.12.1-2).

${ }^{85}$ Como afirma Gascou 1984, 787-98. Veja-se Brandão 2008, 115-37 e 2009b, 357-80.

${ }^{86}$ Veja-se Grimal 1993, 17.

${ }^{87}$ Tit. 8.3: In iis tot aduersis ac talibus non modo principis sollicitudinem sed et parentis affectum unicum praestitit, nunc consolando per edicta, nunc opitulando quatenus suppeteret facultas. Veja-se Gascou 1984, 743.

${ }^{88}$ Aug. 41.1: Liberalitatem omnibus ordinibus per occasiones frequenter exhibuit.

${ }^{89}$ Ves. 17.

${ }^{90}$ Nero 10.1 ; Dom. 9.1. 
aspetos: distribuições às diferentes classes, celebração de jogos ${ }^{91}$, ofertas durante os jogos ${ }^{92}$, embelezamento da Urbe, obras fora da urbe e nas províncias. O evergetismo traduz uma consciência ético-social do poder imperial: é uma forma de promover a concórdia, ao minorar os efeitos decorrentes das desigualdades, e é um meio eficaz de propaganda do regime. Tibério, caracterizado como avaro (pecuniae parcus ac tenax), torna-se modelo da ausência de liberalitas $^{93}$. A avareza de Galba é ridiculizada pela opinião pública através de diversas anedotas ${ }^{94}$. Este imperador acabou por ofender todas as classes, especialmente os soldados pretorianos, a quem nega o donativo habitual na altura da sua aclamação ${ }^{95}$.

Faz parte do conceito «paternalista» do imperador uma função moralizadora ${ }^{96}$, pautada pelo esforço de retorno aos costumes antigos, sobretudo depois de períodos de guerras civis ${ }^{97}$. Augusto, mais uma vez, é modelo: apregoa o retorno ao mos maiorum ${ }^{98}$. A ele se atribui uma série de medidas, adotadas ou reformuladas, que versam sobre a moralização da vida pública e privada: promulga leis sumptuárias, leis de adulteriis et de pudicitia, de ambitu, de maritandis ordinibus $s^{99}$, reprime a usurpação da cidadania ${ }^{100}$, promove o restauro do uso da toga ${ }^{101}$, restabelece a disciplina nos espetáculos ${ }^{102}$. As medidas contra o

${ }^{91}$ Veja-se Della Corte 1967, 100-102.

${ }^{92}$ Veja-se Pociña et Ubiña 1985, 577-602.

${ }^{93}$ Tib. 46-48.

${ }^{94}$ Gal. 12.

${ }^{95}$ Gal. 16.1.

${ }^{96}$ Veja-se Gascou 1984, 743 ss.

${ }^{97}$ Cf. Aug. 32.1: Pleraque pessimi exempli in perniciem publicam aut ex consuetudine licentiaque bellorum ciuilium durauerant aut per pacem etiam extiterant; Tib. 33: (...) atque etiam, si qua in publicis moribus desidia aut mala consuetudine labarent, corrigenda suscepit; $\mathrm{Cl}$. 22: Quaedam circa caerimonias ciuilemque et militarem morem, item circa omnium ordinum statum domi forisque aut correxit aut exoleta reuocauit aut noua instituit; Ves. 9.2: Amplissimos ordines et exhaustos caede uaria et contaminatos ueteri neglegentia purgauit...; 11: Libido atque luxuria coercente nullo inualuerat.

${ }^{98}$ Veja-se Hellegouarc'h 1987, 84.

${ }^{99}$ Aug. 34.1.

${ }^{100}$ Segundo Gascou 1984, 744, Augusto procura evitar a contaminação do sangue romano e a usurpação do direito de cidade numa perspetiva moral, promovendo o prémio do mérito pessoal (iustae causae) contra o favorecimento a clientes (Aug. 40.3). Veja-se Tompson 1981, 35-46. Cláudio, além de proibir aos estrangeiros a utilização indevida de nomes romanos, pune com a decapitação os que usurpam a cidadania romana (Cl.25.3).

${ }^{101}$ Aug. 40.5.

${ }^{102}$ Aug. 44-45. Promoveu a distribuição hierárquica dos lugares dos espectadores e repressão da libertinagem (licentia) dos atores. Tibério expulsou os atores e seus sectários de Roma, apesar dos rogos do povo (Tib. 37.2). Também Domiciano, na parte positiva do principado, promove uma série de medidas de teor semelhante, com vista à correctio morum: os alvos são a licentia theatralis, os scripta famosa, o gesticulandi saltandique studium, bem como as probrosae feminae, os adulteria, a prática homossexual passiva, visada pela lex Scantinia, os incesta das virgens vestais (Dom. 8.3). Veja-se Baumann 1982, 121-22. 
excesso de luxo são louvadas em César ${ }^{103}$, Augusto ${ }^{104}$, Tibério ${ }^{105}$, Vespasiano ${ }^{106}$, e mesmo em Nero, na fase positiva do seu principado ${ }^{107}$. Calígula é louvado (na parte positiva) pelo facto de pretender afogar os spintriae, organizadores de monstrosae libidines ${ }^{108}$.

Um dos deveres dos imperadores é salvaguardar a dignidade das classes mais elevadas. Tibério reprimiu senadores que recorriam a expediente indignos do seu estatuto ${ }^{109}$, matronas adúlteras ${ }^{110} \mathrm{e}$ jovens das classes senatorial e equestre que se expunham voluntariamente a um processo infamante, para não serem impedidos de tomar parte nos jogos teatrais e da arena. Suetónio, que reflete uma conceção tradicional e hierárquica da sociedade, apresenta negativamente os imperadores que tentam subverter esta ordem estabelecida ${ }^{111}$. É que a diferenciação social assenta numa base moral. Sendo a libertas comum a todos os cidadãos livres, a dignitas distingue as classes, segundo uma precisão incluída na Vida de Vespasiano ${ }^{112}$. E o fundamento da dignitas encontra-se não só nos feitos dos antepassados, mas também nas ações louváveis do cidadão ${ }^{113}$.

\section{Poder universalista: Da Urbe ao orbe}

Suetónio, que escrevia no tempo dos primeiros «Antoninos», oriundos da Hispânia, deveria sentir ao seu redor o carácter universal do poder imperial. Além disso, Adriano gostava de viagens. Trata-se de um poder que afeta o orbe, e este mostra-se reconhecido perante os bons príncipes. Tal é o caso do reconhecimento público da obra de Augusto, apresentado em gradação: manifestações de "alguns pais de família», «algumas cidades de Itália», «a maior parte das províncias» e, por fim, «reis amigos e aliados» ${ }^{14}$, honras acaso encarecidas pela

${ }^{103}$ Jul. 43.

${ }^{104}$ Aug. 34.1.

${ }^{105}$ Tib. 34.1.

${ }^{106}$ Ves. 11: restabelecimento de leis sobre libido atque luxuria.

${ }^{107}$ Nero 16.2. Mas, em contrapartida, é-lhe censurado, como ato de rapina, o despojamento das roupas e dos bens de uma matrona vestida com a púrpura proibida (Nero 32.3).

${ }^{108}$ Cal. 16.1.

${ }^{109}$ Tib. 35.2.

${ }^{110}$ Tib. 35.1. Cf. Tac. Ann. 2.50. Condenou ao desterro as matronas que, para contornar a lei, se declaravam prostitutas (Tib. 35.2) - crime de Vistília, segundo Tac. Ann. 2.85.2-3.

${ }^{111}$ Della Corte 1967, 165-90, aponta como critério suetoniano de avaliação dos príncipes a atitude para com a classe a que Suetónio pertencia: os cavaleiros. Esta teoria é refutada por Gascou 1976, 735-40.

${ }_{112}$ Vespasiano destitui senadores e cavaleiros por serem indignissimi, e deixa claro que a distinção entre as duas ordens se faz com base na dignitas e não tanto na libertas, acrescentando que, se um cavaleiro não deve ofender um senador, tem, no entanto, o direito de responder a uma ofensa (Ves. 9.2).

${ }^{113}$ Veja-se Lewis 1991, 3655.

${ }^{114}$ Aug. 59-60. 
generalização ${ }^{115}$. É já em contexto próximo da narrativa da morte, na viagem para Cápreas, que se insere um episódio que significa o reconhecimento do mundo ao poder de Augusto ${ }^{116}$ :

"Quando atravessava, um dia, a baía de Putéolos, os passageiros e os tripulantes de um navio de Alexandria, que acabara justamente de aportar, vestidos de branco e coroados com grinaldas, não só lhe ofereceram incenso, como também o cumularam de bons augúrios e de extraordinários louvores: 'Por ele viviam, por ele navegavam; da liberdade e da felicidade por ele fruíam’».

Trata-se de uma cerimónia litúrgica, como sugere o aparato (roupas, flores, incenso) e o ritmo da invocação: a celebração da paz universal e da segurança nos mares e um reconhecimento ritual da obra de Augusto ${ }^{117}$. No caso de César, salienta-se que ao luto se associaram também numerosos estrangeiros, entre os quais se destacaram, pelos testemunhos de pesar, os Judeus ${ }^{118}$.

Se o poder assenta nas instituições da Urbe, também emana cada vez mais do orbe. Há a consciência de que as forças provinciais podiam retirar ou conferir o império. O fim de Nero fica a dever-se a uma destituição levada a cabo pelo orbe ${ }^{119}$ : «Após ter suportado tal príncipe pouco menos que catorze anos, o orbe da terra destituiu-o finalmente». O princípio do fim foi a revolta dos Gauleses, sob o comando de Víndex: dizia-se por graça que o imperador com o seu canto tinha despertado os Galli, jogando com a ambiguidade do nome que designava quer o povo da Gália, quer a ave ${ }^{120}$. Tácito ${ }^{121}$ dissera que a crise de 68-69 veio revelar algo novo: que o imperador podia ser aclamado em qualquer outro sítio que não Roma, como acontece com Galba, Vitélio e Vespasiano. Galba apresenta-se, teatralmente, como um libertador. Simbolicamente, vai proceder a uma libertação (manumissio) universal ${ }^{122}$ :

${ }^{115}$ Como o exagero de afirmar que cada rei fundou uma cidade com o nome de Cesareia. Veja-se Gascou 1984, 232-38; 240-41.

${ }^{116}$ Aug. 98.2: Forte Puteolanum sinum praeteruehenti uectores nautaeque de naui Alexandrina, quae tantum quod appulerat, candidati coronatique et tura libantes fausta omina et eximias laudes congesserant: 'per illum se uiuere, per illum nauigare, libertate atque fortunis per illum frui'.

${ }^{117}$ Veja-se Rocca-Serra 1974, 671-80; Benario 1975, 84.

$118 \mathrm{Jul}$. 84.5. César concedera-lhes vários privilégios por o terem ajudado na guerra de Alexandria: veja-se Canfora 2000, 233-38.

${ }^{119}$ Nero 40.1: talem principem paulo minus quattuordecim annos perpessus terrarum orbis tandem destituit. Cf. Cal. 56: Ita bacchantem atque grassantem non defuit plerisque animus adoriri.

${ }^{120}$ Nero 45.2 .

${ }^{121}$ Hist. 1.4.

${ }^{122}$ Gal. 10.1: Igitur cum quasi manumissioni uacaturus conscendisset tribunal, propositis ante se damnatorum occisorumque a Nerone quam plurimis imaginibus et astante nobili puero, quem exulantem e proxima Baliari insula ob id ipsum acciuerat, deplorauit temporum statum consalutatusque imperator legatum se senatus ac populi R. professus est. Veja-se Venini 1974, 996-97. 
«Então, como se fosse tratar de uma manumissão, subiu ao tribunal. Diante dele, foi colocado o maior número possível de retratos de condenados e executados de Nero; e ao seu lado, de pé, estava um jovem nobre que, expressamente para este acto, mandara vir da mais próxima das ilhas Baleares, onde estava exilado. Deplorou a situação dos tempos e, depois de ser saudado como imperador, declarou-se legado do senado e do povo romano».

No que respeita a Vespasiano, é o prefeito do Egito, Tibério Alexandre, que leva as suas legiões a prestarem juramento nas calendas de Julho, dia que passou a ser a data oficial do principatus dies. Seguiu-se-lhe o exército da Judeia ${ }^{123}$. E, enquanto envia as tropas para Itália, dirige-se ele próprio para Alexandria para consultar Serápis sobre o grau de certeza do seu poder (de firmitate imperii). Aí é por assim dizer confirmado com uma coroação segundo um ritual que envolve costumes egípcios ${ }^{124}$. Galba e Vespasiano apresentam ascensões ao poder semelhantes, partindo de dois pontos opostos do império. Favorece a ambos uma profecia antiga de que da província que governa sairá um chefe; tal profecia é confirmada por oráculos locais ${ }^{125}$ e pelo achado de uma antiguidade significativa ${ }^{126}$. $\mathrm{Na}$ altura em que o biógrafo escreve, a própria origem dos imperadores espelha o alargamento geográfico na atribuição do poder supremo: um salto do Palatino para a região Sabina, com os Flávios, e para Hispânia, com Trajano e Adriano. O poder oriundo da Hispânia, que se não consolidou em Galba (que, na verdade, representava a velha aristocracia), vai efetivar-se nos Antoninos.

O poder, consolidado na urbe, projeta-se depois sobre o orbe. Uma forma eficaz de propaganda é o espetáculo. A consciência da universalidade torna-se manifesta em César e em Augusto quando oferecem representações teatrais em todas as línguas ${ }^{127}$. Destaca-se sobretudo, entre os espetáculos oferecidos por Calígula, uma novidade ${ }^{128}$ : uma ponte formada com barcas entre Baias e Putéolos, por onde o imperador atravessou em dias sucessivos com um largo séquito de amigos e convidados ${ }^{129}$. Uma das interpretações aduzidas pelo biógrafo patenteia

${ }^{123}$ Cf. Tac. Hist. 2.79. A versão de Josefo (BI 4.601), segundo a qual Vespasiano foi aclamado na Judeia, é rejeitada pelos autores modernos como tendenciosa. Veja-se Cesa 2000, 64.

${ }^{124}$ O liberto Basílides oferece-lhe, segundo o costume local, verbena, coroas e bolos (Ves. 7.1). Segundo Derchain 1953, 261-79, os elementos apresentados (verbena, coroas e bolos) fazem parte do ritual de coroação dos monarcas egípcios. Veja-se também Derchain et Hubaux 1953, 38-52.

${ }^{125}$ Cf. Gal. 9.2; Ves. 4.5; 5.6.

${ }^{126}$ Gal. 10.4; Ves. 7.3.

${ }^{127}$ Jul. 39.1; Aug. 43.1.

${ }^{128}$ Cal. 19.1: Nouum praeterea atque inauditum genus spectaculi excogitauit.

${ }^{129}$ Cal. 19.2. Veja-se Martin 1991, 309; Wardle 1994, 194-96. Para Antonelli 2001, 120-25, é uma forma de demonstrar o poder ilimitado do príncipe, em confronto com o poder dos órgãos constitucionais da República. 
o desejo de emulação da ponte que Xerxes lançou sobre o Helesponto ${ }^{130}$. De facto, no desfile, o príncipe ostentava o pequeno Dario, um refém parto, filho de Artábano III. Segundo outra explicação, seria para aterrorizar os Bretões e Germanos, contra os quais se preparava uma expedição.

De modo semelhante, no que se refere a Nero, o biógrafo coloca explicitamente entre os espetáculos a receção ao rei da Arménia, Tiridates, e a sua coroação em Roma ${ }^{131}$, corolário de um sucesso político e diplomático realizado sob os auspícios do imperador, mas que o biógrafo omite ${ }^{132}$. E a verdade é que, passados vinte anos da sua morte, um falso Nero ainda teve grande acolhimento, sobretudo entre os Partos (e o biógrafo sugere que o episódio se enquadra nas suas lembranças $\left.{ }^{133}\right)$, o que revela a admiração que o Oriente consagrava àquele imperador.

Outra das formas de propaganda de qualquer regime autoritário é a política de grandes construções na urbe e nas províncias. A Urbe era a imagem visível de Roma divinizada. Os bons imperadores são restauradores, tanto quanto possível sóbrios e preocupados com o bem público. No caso de Augusto e Vespasiano, essa tarefa insere-se no programa de restauração da Urbe, depois das guerras civis $^{134}$. Também são aprovadas inicialmente as construções grandiosas de Domiciano ${ }^{135}$, se bem que, na parte negativa da vida, se diga que foram ruinosos os gastos com construções e espetáculos ${ }^{136}$. Quanto a Calígula, parece sugerir-se uma tendência megalómana ${ }^{137}$.

Simbólica poderá ser a construção da famosa Domus Aurea de Nero, com uma estátua colossal no vestíbulo, pórticos imensos, um lago central, campos cultivados e bosques, com requintadas salas de jantar, em que sobressaía a cenatio rotunda, cujo teto simulava a abóbada celeste ${ }^{138}$, conjunto que, para Grimal, corresponderia a uma espécie de microcosmos do mundo mediterrâneo, ao redor do lago central ${ }^{139}$. Torna-se significativa a construção do Anfiteatro Flávio, no

${ }^{130}$ Cal. 19.3. Cf. Hdt. 4.83 ss.

${ }^{131}$ Nero 13.1: Non immerito inter spectacula ab eo edita et Tiridatis in urbem introitum rettulerim.

${ }^{132}$ A vitória diplomática, que resultou na resolução da complicada questão arménio-parta e na pacificação das fronteiras do império. Veja-se Cizek 1982, 145-46; Griffin 1984, 232-33; Fini 1993, 73-78; Shotter 1997, 31-33.

${ }^{133}$ Com a expressão adulescente me...: Nero 57.2. Sobre este falso Nero, veja-se Gallivan 1973, 364-65; Bradley 1978, 294-95.

${ }_{134}$ Aug. 28.3; Ves. 9.1.

${ }^{135}$ Dom. 5. Veja-se Gascou 1984, 668; Jones 1996, 49-50.

${ }^{136}$ Dom. 12.1 .

${ }^{137}$ Cal. 21.

${ }^{138}$ Nero 31.2. Cf. Tac. Ann. 15.42-43. A descrição inclui topoi retóricos contra a sumptuosidade. Veja-se Morford 1968, 158-79; Blaison 1998, 617-24.

${ }^{139}$ Lugar onde, mais tarde, se elevaria o anfiteatro Flávio. Cf. Mart. Spect. 2.5-6. Veja-se Grimal 1955, 16-17; Brandão 2009a, 223-30. 
centro da urbe, integrado no programa de reconstrução em embelezamento da cidade $^{140}$, e em cuja inauguração ${ }^{141}$ se apresenta uma multidão multiétnica, como atesta o poeta Marcial que assistiu ${ }^{142}$.

No centro estava a Urbe romana, de onde todo o poder emanava e para onde todos os povos confluíam. Alterar este estatuto da Urbe ainda parece loucura de tiranos. Sintomático das aspirações autocráticas de César e de Calígula será a suspeita de que tencionam transferir a residência para Alexandria ${ }^{143}$. Muitos destes rumores derivam simplesmente da busca de conformidade com a descrição dos tiranos retóricos, que apresentavam uma série de traços fixados.

Em suma, para Suetónio o poder imperial é uma nova realidade, que substituiu com vantagem a anarquia do final da República, mas que não equivalia a um reinado; um poder que se assenta numa sucessão indefinida e que depende em muito quer de uma espécie de determinismo cósmico representado pelo fatum ou fortuna, quer do carácter de quem o detém, o que justifica também a opção pela biografia como meio privilegiado para analisar sistematicamente o ethos dos principes. Enquanto dependente do carácter do governante, o poder tende a ser encarado de forma paternalista pela atuação sobre os súbditos. Sem perder de vista a tradicional ligação à cidade, o poder tem o seu fundamento na Urbe com a sua vocação universalista, mas está cada vez mais dependente também da aceitação, e por vezes imposição, do orbe. Se as cidades das províncias imitam a Urbe, esta acaba por ser representação cosmopolita do mundo de que é centro. O papel das províncias revela-se cada vez mais importante, mas, por enquanto, a possibilidade de outra capital imperial é considerada uma loucura tirânica.

${ }^{140}$ Ves. 9.1.

${ }^{141}$ Tit. 7.3.

${ }^{142}$ Spect. 3.

${ }^{143} \mathrm{Jul}$. 79.3; Cal. 49.2. Boato levantado certamente a partir da projetada viagem de Calígula a Alexandria, referida por Flávio Josefo (AI 19.81). Segundo Fílon (Leg. 162), Calígula mantinha boas relações com os habitantes de Alexandria e considerava aquela cidade como a única adequada para consagrar a sua divinização (Leg. 338). Veja-se Guastella 1992, 261. Nero, perante a revolta da Gália, chega a sonhar com um reino no Oriente (Nero 40.2), ou que lhe confiem, ao menos, a prefeitura do Egito (Nero 47.2). 


\section{BibliogRAFiA}

Antonelli, G. 2001. Caligola. Imperatore folle o principe inadeguato al ruolo assegnatogli dalla sorte? Roma: Newton \& Compton.

Baumann, R. 1982. “The résumé of legislation in Suetonius." Zeitschrift der Savigny-Stiftung für Rechtsgeschichte: Romanistische Abteilung 99:81-127.

Benario, H. W. 1975. “Augustus prínceps." Aufstieg und Niedergang der römischen Welt ANRW 2 (2):75-85.

Blaison, M. 1998. “Suétone et l' ekphrasis de la Domus Aurea." Latomus 57:617-24.

Bradley, K. R. 1991. “The imperial ideal in Suetonius' Caesares.” In ANRW 2 (33.5):3701-732.

—. 1978. Suetónio. Suetonius' Life of Nero. An Historical Commentary. Bruxelles: Latomus.

Brandão, J. L. 2013. “O destino e a história nas Vidas dos Césares de Suetónio." In Vir bonus peritissimus aeque. Estudos de homenagem a Arnaldo do Espírito Santo, ed. M. Cristina Pimentel e Paulo Farmhouse, 285-98. Lisboa: Centro de Estudos Clássicos da Faculdade de Letras da Universidade de Lisboa.

-2009a. "A ekphrasis suetoniana da Domus aurea." In Linguas e Literaturas. Vol. 1 de Espaços e Paisagens. Antiguidade Clássica e Heranças Contemporâneas, Grécia e Roma, ed. Francisco Oliveira, Cláudia Teixeira e Paula Barata Dias. Coimbra: Associação Portuguesa de Estudos Clássicos, 223-30.

—2009b. Máscaras dos Césares. Teatro e moralindade nas Vidas suetonianas. Coimbra: Centro de Estudos Clássicos e Humanísticos; Imprensa da Universidade de Coimbra / Classica Digitalia.

_ 2008. "Tirano ao tibre! Estereótipos de tirania nas Vidas dos Césares de Suetónio.” Humanitas 60:115-37.

Butler, H. E. e M. Cary. (1993) 1927. Suetónio. Suetonius Diuus Iulius, introduction, bibliography and notes by G. B. Townend. New-York / Oxford: Oxford University Press.

Canfora, L. 2000. Giulio Cesare. Il dittatore democratico. 5a ed. Roma / Bari: Laterza.

Carter, J. M., ed. 2012. Suetonius: Divus Augustus. Bristol: Bristol Classical Press.

Cesa, M., trans. 2000. Svetonio. Vita di Vespasiano. Bologna: Cappelli.

Cizek, E. 1982. Néron. Paris: Fayard.

Della Corte, F. 1967. Svetonio eques Romanus. Firenze: La Nuova Italia.

Derchain, Ph. e J. Hubaux. 1953. “Vespasien au Sérapéum.” Latomus 12:38-52. 
Fini, M. 1993. Nerone. Duemila anni di calunnie. Milano: Mondadori.

Gallivan, P. A. 1973. “The false Neros. A re-examination.” Historia 22:364-65.

Gascou, J. 1984 Suétone historien. Paris: de Boccard.

—. 1976. "Suétone et l’ordre équestre." Revue Des Études Latines 54:257-77.

Giua, M. A. 1990. “Aspetti della biografia latina del primo impero." Rivista Storica Italiana 12: 535-59.

Griffin, M. T. 1984. Nero. The End of a Dynasty. London: Routledge.

Grimal, P. 1993. O Império Romano. Lisboa: Edições 70.

—. 1955. "Sur deux mots de Néron." AFLT Pallas 3:15-20.

Guastella, G. 1999. Gaio Svetonio Tranquillo. L'imperatore Claudio. Venezia: Marsilio.

— Nuova Italia Scientifica.

Hellegouarc'h, J. 1987. "Suétone et le principat d'après la Vie d'Auguste." In Filologia e forme letterarie. Studi offerti a F. della Corte, 79-94. Urbino: Quattro Venti.

Hurley, D. W. 1993. An Historical and Historiographical Commentary on Suetonius' Life of C. Caligula. Atlanta: Scholars Press.

Jones, B. W., ed. 1996. Suetonius. Domitian. Edited with Introduction, Commentary and Bibliography. London, Bristo: Classical Press.

Jones, B. e R. Milns. 2002. Suetonius: the Flavian emperors, a historical commentary. London: Bristol Classical Press.

La Penna, A. 1987. "Cesare secondo Plutarco." In Plutarco, Vite Parallele. Allessandro. Cesare, ed. D. Magnino, 207-306. Milano: Biblioteca Univerzale Rizzoli.

Levick, B. 1999. Tiberius the Politician. London / New York: Routledge.

Lewis, R. G. 1991. "Suetonius' Caesares and their literary antecedents." Aufstieg und Niedergang der romischen Welt 2 (33.5):3623674.

Lindsay, Hugh, ed. 1995. Suetonius, Tiberius. London: Bristol Classical Press.

Louis, N., ed. 2010. Commentaire historique et traduction du Divus Augustus de Suétone. Bruxelles: Éditions Latomus.

Martin, R. 1991. Les douze Césars: du mythe à la réalité. Paris: Les Belles Lettres.

Morford, M. P. 1968. "The distortion of the Domus Aurea tradition." Eranos 66:158-79.

Mottershead, J., ed. 1986. Suetonius. Claudius. Bristol: Bristol Classical Press.

Murison, Charles, ed. 1992. Suetonius. Galba, Otho, Vitellius. London: Bristol Classical Press. 
Oliveira, F. 1992. Les idées politiques et morales de Pline l'Ancien. Coimbra: Instituto Nacional de Investigação Científica / Centro de Estudos Clássicos e Humanísticos.

Pociña, A. e J. F. Ubiña, J. F. 1985. "El evergetismo imperial en Suetonio." Latomus 44:577-602.

Power, T. e R. Gibson. 2014. Suetonius the Biographer. Studies in Roman Lives. Oxford: Oxford University Press.

Rocca-Serra, G. 1974. "Une formule cultuelle chez Suétone (Divus Augustus, 98,2)." In Mélanges de philosophie, de littérature et d'histoire ancienne offerts à P. Boyancé, 671-80. Rome: Palais Farnèse.

Rolfe, J. C. (1913-1914) 1979. Suetónio. Suetonius. Reimpressão, 2 vols. Cambridge (MA) / London: Harvard University Press / Heinemann.

Romilly, J. 1969. "Il pensiero di Euripide sulla tirannia”. Dioniso 43: 175-87.

Seager, R. 1972. Tiberius. London: Eyre Methuen.

Syme, R. 1974. "History or biography. The case of Tiberius Caesar." Historia 23:481-96.

Timonen, A. 1993. "Emperors ars recusandi in biographical narrative." Arctos 27:133-48.

Tompson, L. A. 1981. "The concept of purity of blood in Suetonius' life of Augustus." Museum Africum 7:35-46.

Venini, Paola, ed. 1977. C. Svetonio Tranquillo.Vite di Galba, Ottone, Vitellio, con commentario. Torino: Paravia.

—. 1974. "Sulle Vite suetoniane di Galba, Otone e Vitellio." Rendiconti dell'Istituto Lombardo 108:991-1014.

Wallace-Hadrill, A. 1984. Suetonius. The Scholar and his Caesars. New Haven, CT: Yale University Press.

Wardle, D., trans. 2014. Suetonius. Life of Augustus. Translated with Introduction and Historical Commentary. Oxford: Oxford University Press.

_. 1994. Suetonius' Life of Caligula. A Commentary. Bruxelles: Latomus.

Warmington, B. H., ed. 1999. Suetonius Nero. Text with Introduction and Notes. London: Bristol Classical Press.

Wiedemann, T. 1989. The JulioClaudian emperors: ad 14-70. Bristol: Bristol Classical Press. 
